\title{
Gene Flow between Parents with Different Ploidy Levels in a Natural Population of Leucocoryne Lindley
}

\author{
P. Salas and L. Mansur \\ Facultad de Agronomía, Pontificia Universidad Católica de Valparaíso, Casilla 4-D, Quillota, Chile
}

\begin{abstract}
ADDITIONAL INDEX WORDS. chromosomes, hybridization, outcrossing
Abstract. Gene flow between species of different ploidy levels is important in plant evolution and breeding. A cytological study was conducted on a natural population with individuals belonging to the diploid L. purpurea Gay (2n $=10)$ and to the tetraploid $L$. coquimbensis $F$. Phil $(2 n=18)$ species, as well as intermediate phenotypes of apparent hybrid origin. The genus Leucocoryne is endemic to Chile and it exhibits heterogeneity, presumably genetic, for shape, size, and color of its flowers. The objective of the study was to determine if there is gene flow between species having different ploidy levels. From the karyotypic analyses of the seeds, only parental types having $2 \mathrm{n}=10$ and $2 \mathrm{n}=18$ individuals were observed. However, from the bulb analyses, $2 n=10,2 n=18,2 n=14$, and $2 n=22$ individuals were encountered. The karyotypes of the $2 n=14$ and $2 n=22$ individuals suggest the occurrence of natural interespecific hybridization between species with different ploidy levels in nature. Models which may account for the origin of these genotypes are proposed.
\end{abstract}

The genus Leucocoryne, Alliaceae family (Dahlgren et al., 1985), is a group of bulbous plants endemic to Chile. Their geographic distribution is from Northern Chile, near the city of Iquique (lat. $20^{\circ} 13^{\prime}$ ) to the southern Bio-Bio region, near the city of Concepción (lat. $36^{\circ} 60^{\prime}$ ) where only the species L. alliacea Lindley is present. The highest concentration of species and apparent center of diversity of the bulbs is between lat. $29^{\circ} 56$ and lat. $33^{\circ} 01^{\prime}$ in Coquimbo and Valparaíso regions of central Chile, respectively (Zoellner, 1972).

Due to the great variability of the genus, especially in its floral phenotype, many populations remain taxonomically unclassified (Mansur, 2004). Considering this fact, cytological analyses of the chromosome number might be useful for the classification of the different populations.

The first cytological study in Leucocoryne was conducted by Cave (1939) in L. ixioides Lindley and demonstrated a chromosomal complement of $2 n=18$, composed of seven pairs of metacentric and two pairs of acrocentric chromosomes. In addition to Cave's work, Crosa (1988) studied nine species and observed a chromosomal complement of $2 \mathrm{n}=10$ for seven of them $(L$. pauciflora Phil., L. purpurea, L. alliacea, L. angustipetala Gay., L. odorata Lindley., L. conferta Zoellner, and Leucocoryne sp.) and $2 \mathrm{n}=18$ for two species (L. violascesens Phil. and $L$. ixioides). Crosa (1988) established a basic bimodal complement composed of three metacentric and two acrocentric chromosomes. Araneda et al. (2004) determined the chromosome complement of 11 species/populations. They established that $L$. ixioides, $L$. coquimbensis, L. narcissoides Phil, Leucocoryne sp. Alcones, Leucocoryne sp. Talinay, and Leucocoryne sp. Combarbalá are $2 \mathrm{n}=18 ;$ L. purpurea, Leucocoryne sp. Ñague, Leucocoryne sp. Alicahue, and Leucocoryne sp. Pichicuy are $2 \mathrm{n}=10$; and $L$. coquimbensis var. alba Zoellner is $2 \mathrm{n}=14$. They concluded that Leucocoryne typically has a chromosomal complement of either

Received for publication 26 Apr. 2004. Accepted for publication 20 May 2004. We thank Drs. R. Craig and C. Quiros for their valuable suggestions to improve the manuscript and Mr. Luis Arriagada for his assistance in collecting. This research was supported with funds from Fondo-SAG of the Servicio Agrícola y Ganadero, Chile.
$2 \mathrm{n}=10$ or $2 \mathrm{n}=18$ with a similar number of species or populations at each ploidy level.

The objective of this study is to analyze the karyotypes of individuals from a small population located in the Coquimbo region that exhibits a high phenotypic variability for color, shape, and size of the flowers and in which it is possible to find individuals belonging to $L$. coquimbensis $(2 \mathrm{n}=2 \mathrm{x}=18)$ and to $L$. purpurea $(2 \mathrm{n}=2 \mathrm{x}=10)$ as well as individuals showing intermediate phenotypes between these two species that are possibly natural interespecific hybrids.

\section{Materials and Methods}

Plants. The germplasm used in this study was obtained from seeds and bulbs collected in the field in Oct. 2001, and only seeds in Oct. 2002, from a population of L. purpurea $(2 \mathrm{n}=10)$ and $L$. coquimbensis $(2 \mathrm{n}=18)$, according to the taxonomic key of Zoellner (1972), and their putative hybrids. This population is located on the Region of Coquimbo, Chile (lat. $30^{\circ} 22^{\prime} 29^{\prime \prime} \mathrm{S}$, long. $71^{\circ} 26^{\prime} 17^{\prime \prime} \mathrm{W}, 91 \mathrm{~m}$ altitude). Bulbs from a population of L. coquimbensis var. alba from the region of Coquimbo, which were collected in 1997 and maintained in a greenhouse, were used as controls because they had previously been found to be $2 n$ $=14$ and are likely to be of interspecific hybrid origin (Araneda et al., 2004).

\section{Karyotypic analyses}

SEED. Root tips were obtained from germinated seeds collected at maturity from random individual plants in Oct. 2001 and 2002, thus the phenotypes of the flowers were unknown. After each collection seeds were germinated following the procedure described by De la Cuadra et al. (2002). The seeds were briefly germinated in petri dishes on absorbent paper soaked with distilled water and stored in the dark at $15{ }^{\circ} \mathrm{C}$ until the roots reached a length of 1 to $1.5 \mathrm{~cm}$. From the 2001 collection, 15 seeds from each of 86 plants were used, and for the 2002 collection, 20 seeds from each of 17 plants were used.

Bulb. Twenty-five bulbs were sampled in 2001 at the site from the putative hybrid population, most of them hybrids and a few parental types. Bulb root meristems were obtained from only 
seven of the 25 bulbs, one L. purpurea, one L. coquimbensis, and five of hybrid phenotype. In addition five bulbs belonging to $L$. coquimbensis var. alba were also analyzed.

The squash technique described by Dyer (1963) and adapted by Crosa (1988) and Araneda et al. (2004) was used. Briefly, this consists of a fixing solution of 3 absolute methanol : 1 acetic acid (glacial 100\%) and an orcein lacto-propionic stain. Prior to fixation, the roots were pretreated with a $0.05 \%$ colchicine aqueous solution for $20 \mathrm{~h}$ at room temperature.

The karyotypes were based on the length of each chromosome. Chromosome measurements were made using the computer application MicroMeasure version 3.3 (Reeves and Tear, 2000). Black and white photographs of the preparations were scanned, and Adobe Photoshop 6.0 (Adobe Systems, San Jose, Calif.) software was used to assemble the karyotypes. Chromosome counts were made on at least 10 cells per individual (seed or bulb). Measurements were made on at least one and up to 36 cells per individual, then the average karyotype of individuals with the same number of chromosomes was calculated. Each chromosome was classified according to the terminology of Levan et al. (1964).

The bulbs used for these analyses are maintained in active growth in a greenhouse of the Leucocoryne Breeding Project, at the La Palma Experimental Station in the Facultad de Agronomía of the Pontificia Universidad Católica de Valparaíso, Quillota, Chile.

\section{Results and Discussion}

Low germination in both 2001 (18\%) and 2002 (7\%) seed collections was observed. Fresh seeds of Leucocoryne grown in good conditions have a germination above $90 \%$ (De la Cuadra et al., 2002). The low germination could be attributed to the interspecific hybrid origin of the population and less than optimal growing conditions in the field. The chromosome count showed these seeds to be either $2 n=10$ or $2 n=18$, suggesting that only the seeds with a balanced set of chromosomes were viable. This could not be confirmed because the hybrid bulbs have so far shown only vegetative growth in the greenhouse. Only seven of the bulbs could be analyzed. The others did not produce roots despite being stored at $20^{\circ} \mathrm{C}$ for at least 4.5 months, which should have ended their dormancy (Okhawa et al., 1996). Of these bulbs, one was $2 \mathrm{n}=10$, one $2 \mathrm{n}=18$, two $2 \mathrm{n}=14$, and three $2 \mathrm{n}=22$ (Fig. 1). The $2 \mathrm{n}=10$ and $2 \mathrm{n}=18$ individuals had karyotypes similar to those of the seeds, and were typical of L. purpurea and L. coquimbensis as described by Crosa (1988) and Araneda et al. (2004). The $2 n=10$ karyotypes had three longer metacentric pairs of similar lengths ranging 12-14 $\mu \mathrm{m}$ and two shorter acrocentric pairs ranging 7-10 $\mu \mathrm{m}$, one of the st (sub-telocentric) and one of the $\mathrm{t}$ (telocentric) type (Fig. 1A). The $2 \mathrm{n}=18$ karyotypes had one longer metacentric pair $(16-17 \mu \mathrm{m})$, six metacentric pairs of similar lengths $(12-14 \mu \mathrm{m})$, and two shorter pairs $(7-10 \mu \mathrm{m})$, the eighth pair being of the sm (sub-metacentric) type and the ninth pair of the st type (Fig. 1B).

It was proposed by Crosa (1988) that the $2 n=18$ individuals are tetraploids and might have originated through interespecific hybridization of $2 \mathrm{n}=10$ individuals followed by chromosome number reduction by centric fusion of one of the acrocentric pairs of the $2 \mathrm{n}=10$ species and genome duplication.

Of the five remaining bulbs, two were $2 n=14$ and three were $2 n=22$. Surprisingly, the karyotype of the $2 n=14$ was similar to the $2 \mathrm{n}=14$ for the L. coquimbensis var. alba population described by Araneda et al. (2004). This karyotype has 10 longer metacentric chromosomes and four shorter acrocentric chromosomes, two of

\section{a}

\section{в 888888889888880000}

\section{c lintiritrerill}

\section{Plillillimblidirilimil}

Fig. 1. Karyotypes of bulbs collected in Coquimbo, Chile, from a putative natural hybrid population between Leucocoryne purpurea $(2 \mathrm{n}=10)$ and Leucocoryne coquimbensis $(2 \mathrm{n}=18)$. (A) $2 \mathrm{n}=10$; (B) $2 \mathrm{n}=18$; (C) $2 \mathrm{n}=14$; (D) $2 \mathrm{n}=22$.

the st and two of the t type (Fig. 1C). Both the $2 n=14$ and the $2 n$ $=22$ individuals had the longer metacentric chromosome that is only observed in the $2 \mathrm{n}=18$ species of Leucocoryne. This suggests that one of the parents of these hybrids is L. coquimbensis. We propose that the $2 \mathrm{n}=14$ is an allo-triploid hybrid originating from the cross between the diploid L. purpurea and the tetraploid L. coquimbensis $(2 \mathrm{n}=18)$ as shown in Fig. 2 . The same could be true for L. coquimbensis var. alba in that it may be an interspecific hybrid rather than a botanical variety. This needs to be researched further with a larger number of samples of L. coquimbensis var. alba from various habitats.

Regarding the $2 \mathrm{n}=22$ individuals whose karyotype has 17 metacentric and five acrocentric chromosomes (Fig. 1D), again the lengths of the first and second chromosomes are similar to the first pair of the $2 n=18$ individuals described before and distinct from the other metacentric chromosomes from the $2 \mathrm{n}=$ 10 and $2 n=18$ individuals. We note that there is variability for the position of the centromere of the acrocentric chromosomes especially in the $2 n=18$ and in the $2 n=22$ karyotypes, thus is rather difficult to follow the segregation of these chromosomes without controlled crosses. Evidently, the features of the $2 \mathrm{n}=$ 22 suggest an interspecific hybrid origin for this karyotype. It could have originated from the interespecific hybridization of a nonreduced gamete from a $2 n=18$ individual, and a normal gamete from a $2 n=10$ individual, followed by the loss of an acrocentric chromosome. Thus, these individuals might be pentaploids (Fig. 3).

When interespecific hybridization occurs in a population, fertile, semi-sterile, highly sterile, or fully sterile plants could be expected (Grant, 1981). The $\mathrm{F}_{1}$ partially fertile generation can reproduce by self-pollination, sibling crosses with other hybrid plants, or backcrossing with one or both parents. The resulting offspring can reproduce by both self-fertilization or fertilization/ hibridization with the original plants. The result is a hybrid swarm, a highly variable mixture of species, hybrids, and backcrosses (Grant, 1981). Our results suggest that this is probably what has occurred in the natural population under study over a long period of time. There is coexistence of different species, interspecific hybridization, a high level of phenotypic variability, and individu- 


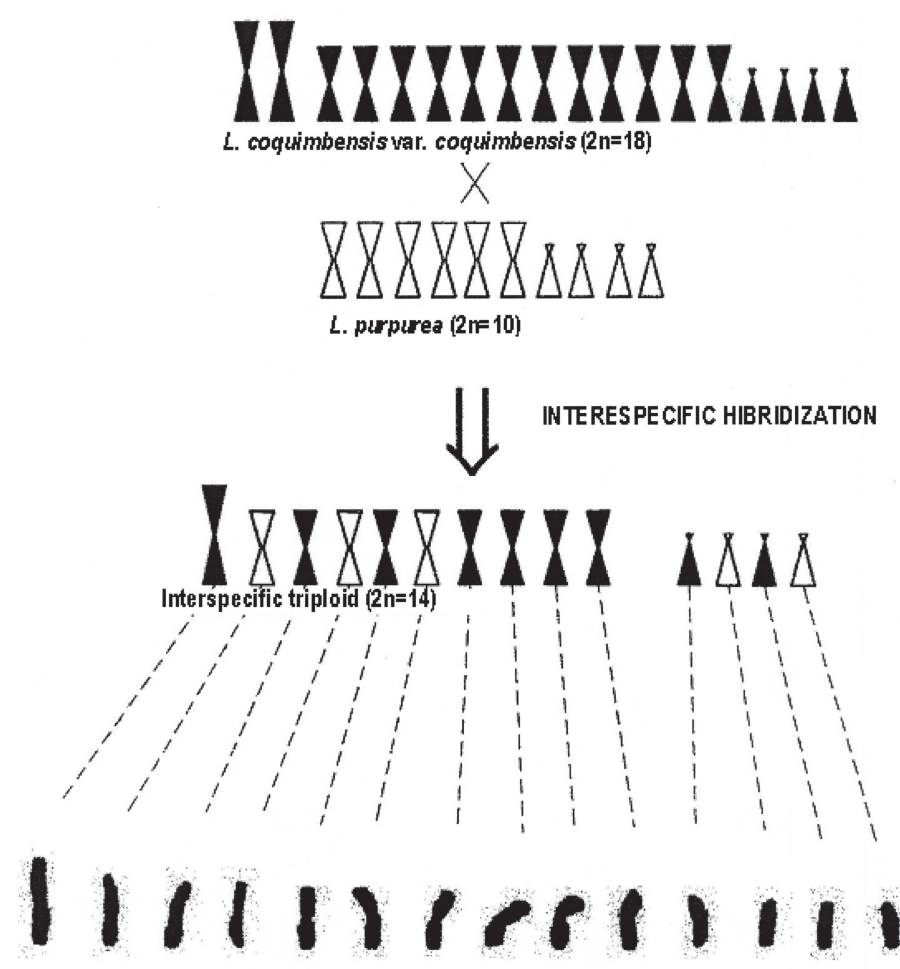

Fig. 2. Proposed model for the formation of a triploid Leucocoryne. $(2 \mathrm{n}=3 \mathrm{x}$ $=14)$.

als with abnormal numbers of chromosomes most likely resulting from crosses and backcrosses among the comprising individuals of the population.

Hybrids swarms are not uncommon in Leucocoryne; in fact, Moreno and Arancio (2001) reported a superposition of species of L. purpurea and L. coquimbensis in Panul, the coastal zone of the Coquimbo region about $41 \mathrm{~km}$ north of our site. A phenotypic analysis suggested hybridization because they found individuals

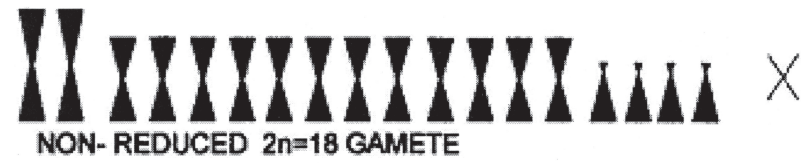
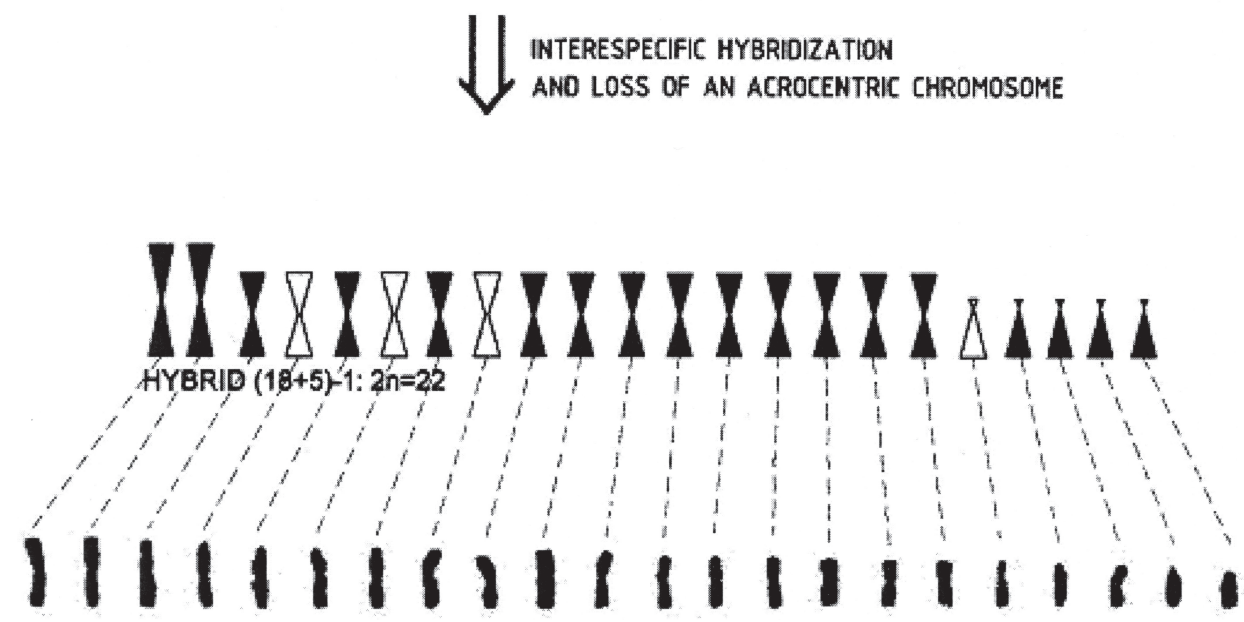

Fig. 3. Proposed model for the formation of a pentaploid Leucocoryne $(2 n=5 x-1=22)$. sharing traits of both species. This supports our hypothesis that there is gene flow between Leucocoryne species with different ploidy levels.

We conclude that in Leucocoryne there is gene flow between species with different ploidy levels in nature. This phenomenon may be enhanced by the overlap of species with different ploidy levels, the outcrossing (self-incompatible) nature of Leucocoryne (Mansur et al., 2004) and its capacity to asexually reproduce unbalanced karyotypes via bulbification. This is important for plant breeding of this genus because it demonstrates the possibility of combining desirable traits of individuals of different species and ploidy levels.

\section{Literature Cited}

Araneda, L., P. Salas, and L. Mansur. 2004. Chromosome numbers in the Chilean endemic genus Leucocoryne (Huilli). J. Amer. Soc. Hort. Sci. 129:77-80.

Cave, M. 1939. Macrosporogenesis in Leucocoryne ixioides Lindl. Cytology 8:407-411.

Crosa, O. 1988. Los cromosomas de nueve especies del género chileno Leucocoryne Lindley (Alliae - Alliacea). Boletín de Investigación. Facultad de Agronomía. Universidad de la República. Uruguay 17:1-12.

Dahlgen, R., H. Clifford, and P. Yeo. 1985. The families of the monocotyledons. Springer Verlag, Berlin.

De la Cuadra, C., L. Mansur, G Verdugo, and L. Arriagada. 2002. Deterioro de las semillas de Leucocoryne spp. en función del tiempo de almacenaje. Agricultura Técnica (Chile) 62:46-55.

Dyer, E. 1963. The use of lacto-propionic orcein in rapid squash methods for chromosome preparations. Stain Technol. 38:85-90.

Grant, V. 1981. Plant speciation. 1 ${ }^{\text {st }}$ ed. Columbia Univ. Press, New York.

Levan, A., K. Fredga, and A. Sandberg. 1964. Nomenclature for centromeric position on chromosomes. Hereditas 52:201-220.

Mansur, L. 2004. Life cycle, self-incompatibility, and genetic plasticity in the design and color of Leucocoryne flowers, p. 9-15. In: Leucocoryne: A native Chilean genus and its use as a garden plant. Reimco Ltda., Viña del mar, Chile.

Mansur,L., M. Gonzalez, I. Rojas, and P. Salas. 2004. Self-incompatibility in the Chilean endemic genus Leucocoryne. J. Amer. Soc. Hort. Sci. 129:XXX-XXX.

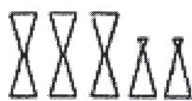

$2 n=10$ GAMETE Moreno, R. and G. Arancio. 2001. Posibles híbridos naturales entre dos especies del género Leucocoryne. Gayana 58(1):86-87.

Okhawa, K., H.H. Kim, E. Nitta, and Y. Fukaswa. 1996. Storage temperature and duration affect flower bud development, shoot emergence, and flowering of Leucocoryne coquimbensis. F. Phil. J. Amer. Soc. Hort. Sci. 123(4):586:591.

Reeves, A. And J. Tear. 2000. MicroMeasure. 26 May 2004. <http://www.colostate. edu/Depts/Biology/Micromeasure $>$

Zoellner, O. 1972. El género Leucocoryne. Anales Museo Historia Natural Valparaíso 5: 9-83. 